tested 346 infants at risk and showed that 20 of the 21 surviving infants who gave negative results to brain stem audiometry also failed on the otoacoustic test. ${ }^{1+}$ This work also highlighted a major problem - that of validating methods of testing senses in the newborn baby. This has to be by follow up, checking the outcome with the testing methods that become possible in the older infant. Stevens's group found a poor correlation between distraction testing of the babies' hearing at 8 months of age and brain stem audiometry in the newborn, a discrepancy confirmed by others. ${ }^{15}$ We must now be more cautious in interpreting the results of electrophysiological tests in the newborn. Babies who give negative results will need retesting several times during the first year. Though the early fitting of hearing aids is desirable, the degree of hearing impairment needs to be clearly established, particularly as maturation of the auditory pathways may be taking place, although delayed.

Similar problems and challenges occur in testing vision in newborn babies. ${ }^{16}{ }^{17}$ Behavioural responses are familiar to the mother, with the baby blinking to bright light, fixating, and following a red woollen ball or a flashing light. Babies turn their heads to a diffuse light but (like turning to sound) this test may not be reliable, especially in preterm infants. All these responses give a qualitative indication of vision. Optokinetic nystagmus can be shown when a striped tape or drum is moved in a temporal to nasal direction across the newborn baby's field of vision and gives a valuable but crude indication that vision is present. Electrophysiological recording of the visual evoked potential to a flash gives limited useful information because of great individual variations and because it relates as much to general cerebral function as to visual outcome. ${ }^{18}$ Visual evoked potentials to patterns may give a measure of visual function but only after the age of 2 months. The best method of measuring visual acuity is to use the preferential looking technique. This is based on the observation of Fantz 30 years ago that patterned objects are visually interesting to infants. ${ }^{19}$ The latest version, called the acuity card procedure, uses patterned and plain stimuli mounted in pairs on cards, and these can be used successfully even in the neonatal intensive care unit. ${ }^{17}$

Much fascinating and enjoyable research is being done into the ability of babies to discriminate and respond to smell, taste, and touch. ${ }^{3}$ We should also be glad that at long last there is widespread acceptance of the fact that newborn babies do experience real pain and need postoperative analgesia like the rest of us. ${ }^{20}$

DAVID A CURNOCK

Consultant Paediatrician

City Hospital,

Nottingham NG5 1PB

1 Shakespeare W. As You Like It. In: Craig WJ, ed. The complete works of William Shakespeare. London: Oxford University Press, 1955:2270. (Act 2, scene 7, lines 143-4.

James $\mathrm{W}$. The principles of psychology. New York: Holt, 1890

MacFarlane A. The psychology of childbirth. London: Fontana, 1977.

4 Fantz RL. The origins of form perception. Scientific American 1961;204 (May):66-72.

5 Wolff PH. The development of attention in young infants. Ann NY Acad Sci 1965;118:815-30.

6 Prechtl $\mathrm{H}$, Beintema D. The neurological examination of the full-term newborn infant. London: Spastics International Medical Publications, 1964. (No 12.)

Brazelton TB. Neonatal behaviour assessment scale. 2nd ed. London: Spastics International Medical Publications, 1984. (No 88 .)

8 Markides A. Age of fitting of hearing aids and speech intelligibility. Br $\mathrm{J}$ Audiol 1986;20:165-8.

9 Dubowitz. LMS. Clinical assessment of the infant nervous system. In: Levene MI, Bennett MJ, Punt J, eds. Fetal and neonatal neurology and neurosurgery. Edinburgh: Churchill Livingstone, Punt J, eds.

10 Bhattacharya J, Bennett MU, Tucker SM. Long term follow up of newborns tested with the auditory response cradle. Arch Dis Child 1984;59:504-11.

11 McCormick B, Curnock DA, Spavins F. Auditory screening of special care neonates using the auditory response cradle. Arch Dis Child 1984;59:1168-72.

12 Mason SM. Automated system for screening hearing using the auditory brainstem response. $\mathrm{Br} \mathcal{F}$ Audiol 1988;22:211-3.

13 Kemp DT. Stimulated acoustic emissions from within the hearing system. $\mathcal{J}$ Acoust Soc Am 1978;64:1386-91

14 Stevens JC, Webb HD, Hutchinson J, Connell J, Smith MF, Buffin JT. Click evoked otoacoustic emissions compared with brain stem electric response. Arch Dis Child 1989;64:1105-11.

15 Murray AD, Javel E, Watson CS. Prognostic validity of auditory brainstem evoked response screening in newborn infants. Am F Otolaryngol 1985;6:120-31.
16 Van Hof-van Duin J, Mohn G. Vision in the preterm infant. In: Prechul HFR, ed. Continuity an Hof-ran Duin J, Mohn G. Vision in the preterm infant. In: Precht HFR, ed. Continuty of neural functions from prenatal to
Publications, 1984;93-114. (No 94.)

7 Fielder AR. Disorders of vision. In: Levene MI, Bennett MJ, Punt J, eds. Fetal and neonatal neurology and neurosurgerv. Edinburgh: Churchill Livingstone, 1988:517-34.

18 Mushin J. Visual evoked potentials. In: Levene MI, Bennett MJ, Punt J, eds. Fetal and neonatal neurology and neurosurgerv. Edinburgh: Churchill Livingstone, 1988:206-12.

19 Fantz RL. Pattern vision in young infants. Psychological Record 1958;8:43-7.

20 Chomara IA. Pain relief. Arch Dis Child 1989;64:1101-2.

\section{Cytotoxic drugs for gastric and colorectal cancer}

\section{More effective palliation may now be possible}

Cancers of the stomach, colon, and rectum account for 25000 deaths annually in Britain. Surgery is the mainstay of treatment, but it yields a five year survival of only $5-10 \%$ for patients with gastric cancer ${ }^{1}$; the results are better in colorectal cancer, but, nevertheless, $55-60 \%$ of patients ultimately die of recurrent disease. Local treatment is inadequate for many patients, and systemic drug treatment is the only option.

These tumours are generally regarded as being resistant to cytotoxic drugs. Indeed, in Britain most clinicians would not treat patients outside a clinical trial - an entirely reasonable approach. Yet, while we await the "magic bullet" patients continue to present with symptomatic disease, and for them tomorrow's treatment is too late. In these circumstances the antimetabolite fluorouracil has been the first choice. When given as an intravenous bolus (according to a variety of schedules) regression of the tumour may be seen in $15-20 \%$ of patients with gastric cancer and $10-20 \%$ of patients with colorectal cancer. Remissions are generally short lived, however, and complete remissions are extremely rare.

So could these results be improved? In gastric cancer combinations of cytotoxic drugs have been investigated for over 20 years. In the late 1970s the FAM regimen (fluorouracil, doxorubicin (Adriamycin), and mitomycin) was reported to produce more frequent $(35-50 \%)$ and durable partial responses, ${ }^{2.3}$ and in some centres it became regarded as a "standard" treatment. Complete remissions remained unusual, however, and a subsequent randomised trial showed no advantage of FAM over fluorouracil given alone. ${ }^{+}$ More recently cisplatin has emerged as an active agent in gastric cancer. Several studies of cisplatin given as a single agent-which included patients previously treated with chemotherapy-reported regression of the tumour in a quarter of cases. ${ }^{5-7}$ When cisplatin has been used in combination with fluorouracil, doxorubicin, or etoposide responses have been observed in $45-70 \%$ of patients, ${ }^{8-10}$ and-more importantly-histologically validated complete remissions were reported in $18 \%$ of a group of patients who had preoperative chemotherapy. ${ }^{11}$

Chemotherapy should be delivered with the minimum of toxicity. Cisplatin may induce severe vomiting, a symptom which is particularly stressful in patients with upper gastrointestinal cancers. As anti-emetic treatment has become more effective the therapeutic window of palliative treatment has been gradually enlarged. ${ }^{12}$ Nevertheless, so far adjuvant chemotherapy has failed to make any real impact on the survival of patients with gastric cancer. A recently completed pilot study of adjuvant intraperitoneal cisplatin has confirmed the feasibility of this approach in gastric cancer, a disease in which up to a third of patients have malignant cells in the peritoneal washings taken at the time of "curative" surgery. 
This treatment might be combined with more effective systemic treatment and needs further evaluation.

Fluorouracil exerts its cytotoxicity through several pathways, including inhibition of the enzyme thymidylate synthase, which is achieved by the formation of a complex consisting of 5-fluorodeoxyuridinemonophosphate, methylene tetrahydrofolate, and the enzyme. Formation of the complex is favoured by the presence of reduced folates, and administration of folinic acid with fluorouracil increases the cytotoxic effect. Several randomised trials in patients with colorectal cancer have shown that the combination of fluorouracil and folinic acid produce higher response rates $(33-48 \%),{ }^{1+-18}$ and two trials have shown a prolongation of survival when compared with those of fluorouracil alone. ${ }^{17} 18$ In one of these studies the survival time for patients given the combination was twice that of those given fluorouracil as a single agent (12 $v$ six months), and treatment was associated with an improvement in the quality of life. ${ }^{17}$ The combination produces more gastrointestinal toxicity than fluorouracil alone, and particular care must be taken in elderly patients, in whom diarrhoea may be severe and life threatening. The ideal dose and scheduling for the administration of fluorouracil and folinic acid is not established.

Another method of improving the response to fluorouracil is by giving it as a continuous intravenous infusion. In a randomised trial Lokich et al compared fluorouracil $300 \mathrm{mg} / \mathrm{m}^{2}$ a day for 12 weeks with fluorouracil $600 \mathrm{mg} / \mathrm{m}^{2}$ as a daily intravenous bolus for five days every five weeks. ${ }^{19}$ The partial response rate in the infusion arm was $30 \%$ compared with $7 \%$ in the bolus arm, but there was no overall improvement in survival. When given by continuous infusion fluorouracil is well tolerated; suppression of the bone marrow and stomatitis are unusual, but up to a quarter of patients develop erythema and desquamation of the hands and feet the so called hand-foot syndrome, which, rather curiously, responds to oral pyridoxine. ${ }^{20}$ In laboratory studies interferon alfa enhances the cytotoxicity of fluorouracil, and the early clinical results look promising. In a phase II trial the combination produced partial remissions in 13 out of 16 patients with untreated metastatic cancer of the colon. Fluorouracil was given at a dose of $750 \mathrm{mg} / \mathrm{m}^{2}$ daily as a continuous infusion for five days followed by a weekly bolus injection of $750 \mathrm{mg} / \mathrm{m}^{2}$. Interferon was given in doses ranging from $9 \mathrm{MU}$ subcutaneously three times weekly to $12 \mathrm{MU}$ subcutaneously daily. The toxic effects included myelosuppression, stomatitis, and diarrhoea, and these were more frequent with the higher doses, whereas the responses were seen mainly at the lower doses. ${ }^{21}$

Regional chemotherapy has also been studied for improving the results of cytotoxic drug treatment of colorectal cancer. For patients with unresectable liver metastases high doses of fluorouracil or floxuridine given through the hepatic artery produce increased response rates (40-60\%), and because of the effect of first pass hepatic metabolism systemic toxicity such as stomatitis and myelosuppression are unusual. Until recently the effect that this treatment has on overall survival was not clear. At this year's meeting of the American Society of Clinical Oncology, however, the results of a randomised trial were presented by O'Connell et al, which compared intra-arterial floxuridine with intravenous fluorouracil. ${ }^{22}$ This study confirmed the higher response rate $(54 \% v 21 \%)$ for regional treatment but found no improvement in the overall survival or time to disease progression in the regional treatment group, mainly because of the progression of tumour deposits outside the liver. On the basis of these results intrahepatic floxuridine should not be abandoned, but clearly any useful effect on survival will be achieved only if it is combined with effective systemic treatment.

Modest improvements in treating metastatic gastric and colorectal cancer have taken place in the past few years. In advanced disease none of these treatments are curative, but their application to adjuvant chemotherapy deserves further study. The combination of cytotoxic drugs and treatments which modify the biological response, such as interferon, may hold out more promise if the early results are confirmed

DAVID CUNNINGHAM

Senior Lecturer and Consultant Physician,

Section of Medicine,

Institute of Cancer Research,

Royal Marsden Hospital,

Sutton,

Surrey SM2 5PT

1 Cunningham D, Hole D, Carter DC, Taggart DJ, Soukop M, McArdle CS. An evaluation of the prognostic factors in gastric cancer: the effects of chemotherapy on survival. $\mathrm{Br} f$ Surg 1987;74:715-20.

2 MacDonald JS, Woolley PV, Smythe T, Ueno W, Hoth D, Schein P. 5-Fluorouracil, adriamycin and mitomycin-C $($ FAM $)$ combination chemotherapy in the treatment of advanced gastric cancer. Cancer 1979;44:42-7.

3 Cunningham D, Soukop M, McArdle CS, et al. Advanced gastric cancer: experience in Scotland using 5-fluorouracil, adriamycin and mitomycin-C. Brf Surg 1984;71:673-6.

+ Cullinan SA, Moertel CG. Fleming TR, et al. A comparison of three chemotherapeutic regimens in Cullinan SA, Mortel CG, Fleming TR, et al. A comparison of three chemotherapeutic
the treatment of advanced pancreatic and gastric carcinoma. fAMA 1985;253:2061-7.

5 Beer $M$, Cocconi $G$, Ceci $G$, Varini $M$, Cavalli F. A phase II study of cisplatin in advanced gastric cancer. Eur f Cancer Clin Oncol 1983;19:717-20.

6 Leichman L, McDonald B, Dindogru A, Sampson M, Vaitkevicius VK. Cisplatin: an active drug in the treatment of disseminated cancer. Cancer 1984;53:18-22.

7 Lacave AJ, Wils J, Diaz-Rubio E, et al. Cisplatin as second-line chemotherapy in advanced gastric adenocarcinoma. A phase II study of the EORTC Gastrointestinal Tract Cancer Cooperative Group. Eur f Cancer Clin Oncol 1985;21:1321-4.

8 Lacave AJ, Anton-Aparicio L, Gonzalez-Baron $M$, et al. Cisplatin (CDDP) and 5-fluorouracil $5 \mathrm{FU}) 120 \mathrm{hr}$ infusion for advanced gastric cancer (GC): a phase II multicenter study. Proceeding of the American Society of Clinical Oncology 1987;6:91.

9 Preusser $\mathrm{P}$, Wilke $\mathrm{H}$, Achterrath W, et al. Advanced gastric carcinoma: a phase II study with etoposide $(\mathrm{E})$, adriamycin $(\mathrm{A})$ and split course cisplatin $(\mathrm{P})=\mathrm{EAP}$. Proceedings of the American Society of Clinical Oncology 1987;6:75.

10 Wagener DJ, Yap SH, Wobbes T, et al. Phase II trial of 5-fluorouracil, adriamycin and cisplatin FAP) in advanced gastric cancer. Cancer Chemother Pharmacol 1985;15:86-7.

11 Preusser P, Fink U, Gunzer U, et al. Neoadjuvant chemotherapy with etoposide/adriamycin, cisplatin (EAP) in locally advanced gastric cancer. Proceedings of the American Society of Clinical Oncology 1988;7:100

12 Cunningham D, Hawthorn J, Pople A, et al. Prevention of emesis in patients receiving cytotoxic drugs by $\mathrm{GR} 38032 \mathrm{~F}$, a selective $5 \mathrm{HT}^{\prime}$ receptor antagonist. Lancet 1987;i:1461-3.

3 Cunningham D, Sauven P, Parker $M$, et al. Intraperitoneal cisplatin-a new approach to the adjuvant treatment of gastric cancer. Eur F Surg Oncol 1989;15:190.

14 Petrelli N, Herrera L, Rustum Y, et al. A prospective randomised trial of 5-fluorouracil v 5 -fluorouracil and high dose leucovorin vs 5 -fluorouracil and methotrexate in previously untreated patients with advanced colorectal carcinoma. $f$ Clin Oncol 1987;5:1559-65.

15 Nobile UT, Vidili MG, Sobrero A, et al. 5-Fluorouracil alone or combined with high dose folinic acid in advanced colorectal cancer patient: a randomised trial. Proceedings of the American Society of Clinical Oncology 1988;7:97.

16 Doroshow JH, Bertrand $M$, Multhauf P', et al. Prospective randomised trial comparing 5-FU versus 5-FU and high dose folinic acid for treatment of advanced colorectal cancer. Proceedings of the American Society of Clinical Oncology 1987;6:96.

170 Connell MI. A phase III trial of 5 -fluorouracil and leucovorin in the treatment of advanced colorectal cancer. Cancer 1989;63:1026-30.

18 Frlichman $C$. Fine $S$, Wong $A$, Elhakim T. A randomised trial of fuorouracil and folinic acid in patients with metastatic colorectal carcinoma. $\mathcal{F}$ Clin ()ncol 1988;6:469-75.

19 Lokich JJ, Ahlgren JD, Gullo JJ, Philips JA, Fryer JG. A prospective randomised comparison of continuous infusion fluorouracil with a conventional bolus schedule in metastatic colorectal carcinoma: a mid-Atlantic oncology program study. 7 Clin Oncol 1989;7:425-32

20 Mortimer J, Anderson I. Managing the toxicities unique to high dose leukovorin (CF) and fluorouracil (FU). Proceedings of the American Society of C.linical Oncologv 1989;8:98.

21 Wadler S, Lyver A, Goldman M, et al. Therapy with 5-fluorouracil (5FU) and recombinant alpha-2a-interferon (IFN) in refractory (il malignancies. Proceedings of the American Socielv of Clinical Oncologv 1989;8:99.

$22 \mathrm{O}^{\prime}$ Connell $\mathrm{M}$, Mailliard J, Martin J, et al. A controlled trial of regional intra-arterial FUDR versus s'stemic $5 \mathrm{FU}$ for the treatment of metastatic colorectal cancer confined to the liver. Procedings of the American Soctety of Climical Oncology 1989;8:98. 